\title{
BMJ Open Women's perception of risks of adverse fetal pregnancy outcomes: a large-scale multinational survey
}

\author{
Irene Petersen, ${ }^{1}$ Rachel L McCrea, ${ }^{1}$ Angela Lupattelli, ${ }^{2}$ Hedvig Nordeng ${ }^{2,3}$
}

To cite: Petersen I,

McCrea RL, Lupattelli A, et al. Women's perception of risks of adverse fetal pregnancy outcomes: a large-scale multinational survey. BMJ Open 2015;5:e007390. doi:10.1136/bmjopen-2014007390

- Prepublication history and additional material is available. To view please visit the journal (http://dx.doi.org/ 10.1136/bmjopen-2014007390).

Received 8 December 2014 Revised 29 April 2015 Accepted 7 May 2015

\section{CrossMark}

\footnotetext{
${ }^{1}$ Department of Primary Care and Population Health, UCL, London, UK

${ }^{2}$ Department of

PharmacoEpidemiology and Drug Safety Research Group, School of Pharmacy, University of Oslo, Oslo, Norway

${ }^{3}$ Division of Mental Health, Norwegian Institute of Public Health, Oslo, Norway
}

Correspondence to Dr Irene Petersen; i.petersen@ucl.ac.uk

\section{ABSTRACT}

Objective: To determine pregnant women and new mothers' perception of risks in pregnancy.

Design, settings and participants: This was a large-scale multinational survey including 9113 pregnant women and new mothers from 18 countries in Europe, North America and Australia.

Main outcomes: Risk perception scores (0-10) for harmful effects to the fetus were derived for:

(1) medicines (over-the-counter medicine and prescribed medicine), (2) food substances (eggs and blue veined cheese), (3) herbal substances (ginger and cranberries) (4) alcohol and tobacco, and (5) thalidomide.

Results: Overall, 80\% (6453/8131) of women perceived the risk of giving birth to a child with a birth defect to be $\leq 5$ of 100 births. The women rated cranberries and ginger least harmful (mean risk perception scores 1.1 and 1.5 of 10 , respectively) and antidepressants, alcohol, smoking and thalidomide as most harmful (7.6, 8.6, 9.2 and 9.4 out of 10, respectively). The perception varied with age, level of education, pregnancy status, profession and geographical region. Noticeably, $70 \%$ had not heard about thalidomide, but of those who had (2692/9113), the risk perception scores were $0.4-0.5$ points lower in women below 25 years compared to women aged 26-30 years.

Conclusions: In general, women perceived the risks of giving birth to a child with birth defects low, but there were substantial disparities between women's perceived risks and the actual risks when it comes to over-the-counter agents against nausea and prescribed medication. The study revealed that few women knew of thalidomide, suggesting that the general awareness among women of the teratogenic effects of thalidomide is declining, but it has left a general scepticism about safety of medication in pregnancy. This may have some severe consequences if women are left without medical treatments in pregnancy.

\section{INTRODUCTION}

Pregnancy is an important period in many women's lives and a period where they may consider their own health as well as that of their future child. Some women may

\section{Strengths and limitations of this study}

First large-scale multinational survey of women's actual perception of risks of a range of substances in pregnancy.

- It is an internet survey with potential for selection bias towards the more literate population, although internet penetration rate is high among women of child-bearing age.

- The survey did not go into detailed questioning about women's perception of what constitute harmful effects, but left this to the individual women to define.

experience a conflict between the management of the two. The thalidomide scandal back in the early 1960s heightened the awareness of the potential risks associated with medicines taken in pregnancy. ${ }^{1}$ However, the guidance around prescribed medicine is still relatively vague and sometimes without clear evidence base. For example, the British National Formulary (BNF) provides the following advice "Drugs should be prescribed in pregnancy only if the expected benefit to the mother is thought to be greater than the risk to the fetus and all drugs should be avoided if possible during the first trimester..." Further the BNF advises that newer and untried drugs should be avoided if possible. This lingering uncertainty may result in many women, despite their own need for treatment, choosing not to take the medication in pregnancy. ${ }^{2-7}$

Women also make important decisions in pregnancy in terms of other exposures, for example, alcohol, smoking and certain food items. They may seek advice from different sources depending on which services are available ${ }^{89}$ but the final decisions are likely to be influenced by the perceived risks, which often may be higher than the actual risks. ${ }^{6} 10$ Thus, a Norwegian survey among 1548 pregnant women and new mothers suggested that 
perceived risks for antidepressants, smoking and alcohol were on par with thalidomide. ${ }^{4}$ Likewise, a Spanish study which examined the perceived risks associated with 14 specific medications also demonstrated that the perceived risk was higher than the actual risks for all medications. ${ }^{6}$ This was the case not only for pregnant women, but also for healthcare professionals and medical students. ${ }^{6}$ Women's perception of risks may vary depending on age, self-image, history and healthcare. ${ }^{11-}$ 13 Likewise, women with complications during pregnancy may be more aware of specific risks than women with no complications. ${ }^{14}$

In a multinational internet-based population survey, we further examined the perception of risks of adverse fetal outcomes of medication, food items and other exposures in pregnancy in women living in different geographical regions in Europe, North America and Australia.

\section{METHODS}

Data

This study was based on data from an international survey of women in Europe, North America and Australia (table 1). Hence, member countries of the European Network of Teratology Information Services (ENTIS), the Organisation of Teratology Information Specialists (OTIS) in North America, MotherSafe in Australia, and European institutions conducting public health research were invited to act as national coordinators of the project. Of these, 18 countries participated (Australia, Austria, Canada, Croatia, Finland, France, Iceland, Italy, Netherlands, Norway, Poland, Russia, Serbia, Slovenia, Sweden, Switzerland, UK and USA).

The questionnaires were initially developed in Norwegian and English; these were translated into the other relevant languages and then rolled out via QuestBack (http://www.questback.com/) after being piloted in four countries in order to evaluate its comprehension and suitability to the national setting. The questionnaire was open to the public via utilisation of banners on 1-4 websites, social networks and/or pregnancy forums per country commonly visited by pregnant women. Websites were selected on the basis of the number of daily users. Information about recruitment tools utilised and internet penetration rates in each participating country are described in details elsewhere. ${ }^{15}$ The data were collected over a 2-month period for each country in 2011-2012. The survey asked women to provide some general demographic and pregnancy details. Then women were asked to provide their assessment of pregnancy risks in general, as well as their perception of the harm of 13 substances: paracetamol, antibiotics (eg, penicillins), antidepressants, thalidomide, swine influenza-vaccine, over-the-counter (OTC) agents to fight nausea, ginger, cranberries, blue veined cheese, eggs, alcohol in the first trimester, smoking and dental X-ray. Hence, women were asked the following questions:
Table 1 Characteristics of women completing the online survey $(n=9113)$

\begin{tabular}{|c|c|c|}
\hline & $\mathbf{N}$ & Per cent \\
\hline \multicolumn{3}{|l|}{ Age (years) } \\
\hline $15-20$ & 294 & 3.2 \\
\hline $21-25$ & 1659 & 18.2 \\
\hline $26-30$ & 3310 & 36.3 \\
\hline $31-35$ & 2625 & 28.8 \\
\hline $36-40$ & 1036 & 11.4 \\
\hline $41-55$ & 189 & 2.1 \\
\hline \multicolumn{3}{|l|}{ Marital status } \\
\hline Married/cohabiting & 8578 & 94.1 \\
\hline Divorced/single/other & 535 & 5.9 \\
\hline \multicolumn{3}{|l|}{ Highest education completed } \\
\hline $\begin{array}{l}\text { Primary/secondary school (8-9 years } \\
\text { of education) }\end{array}$ & 380 & 4.2 \\
\hline $\begin{array}{l}\text { High-school ( } 11-13 \text { years of } \\
\text { education) }\end{array}$ & 2574 & 28.2 \\
\hline University or college & 5120 & 56.2 \\
\hline Other education & 1039 & 11.4 \\
\hline \multicolumn{3}{|l|}{ Work situation at the start of pregnancy } \\
\hline Student & 798 & 8.8 \\
\hline Housewife & 780 & 8.6 \\
\hline $\begin{array}{l}\text { Healthcare personnel, that is, } \\
\text { physician, nurse or pharmacist }\end{array}$ & 1236 & 13.6 \\
\hline Employed in another sector & 5417 & 59.4 \\
\hline Job seeker & 413 & 4.5 \\
\hline Other/unknown & 469 & 5.1 \\
\hline \multicolumn{3}{|l|}{ Region } \\
\hline Northern Europe* & 2820 & 30.9 \\
\hline Western Europe† & 3201 & 35.1 \\
\hline Eastern Europe $\ddagger$ & 2342 & 25.7 \\
\hline North America§ & 533 & 5.8 \\
\hline Australia & 217 & 2.4 \\
\hline \multicolumn{3}{|l|}{ Pregnancy status } \\
\hline Currently pregnant & 4938 & 54.2 \\
\hline New mother: child aged 0-28 weeks & 2173 & 23.8 \\
\hline New mother: child aged >29 weeks & 2001 & 22.0 \\
\hline \multicolumn{3}{|l|}{ Previous children } \\
\hline None & 4602 & 50.5 \\
\hline One & 3229 & 35.4 \\
\hline Two & 983 & 10.8 \\
\hline More than two & 299 & 3.3 \\
\hline
\end{tabular}

${ }^{*}$ Finland $(n=574)$, Iceland $(n=71)$, Norway $(n=1288)$, Sweden $(n=887)$.

†Austria $(n=82)$, France $(n=374)$, Italy $(n=926)$, The Netherlands $(n=81)$, Switzerland $(n=618)$, UK $(n=1120)$.

$\neq$ Croatia $(n=286)$, Poland $(n=679)$, Russia $(n=1008)$, Serbia $(n=220)$, Slovenia $(n=149)$.

$\S$ Canada $(n=236)$ USA $(n=297)$.

- "Among 100 healthy women in a healthy environment, how many do you think will give birth to a child with a birth defect?"

- "Here below is a list with various medicines, food and other substances. Please indicate how harmful you think they are for the foetus in a scale from 0 to 10 , where 0 corresponds to 'not harmful' and 10 to 'very harmful'. If you have not heard before about such substance, tick 'unknown substance'." 
- For all exposures (except thalidomide), the actual risk of congenital malformation is considered to be less than 5\%. Numeric rating scales ranging from 0 (not harmful for the foetus) to 10 (very harmful to the foetus) were utilised. Women could also select the option 'unknown substance', if applicable.

\section{Statistical analyses}

\section{Summary of background characteristics}

We summarised background characteristics of the women who responded to the questionnaires and estimated their baseline perception of giving birth to a child with a birth defect. We then calculated the overall median, mean and SD of the perceived risk scores for each of the substances and by geographical regions (Northern Europe, Western Europe, Eastern Europe, North America, and Australia).

\section{Grouping of the substances for further analyses}

For our next analysis, our outcome variables were the risk perception scores for the 13 substances. However, to reduce the number of analyses, we first explored whether we could combine similar substances into a smaller number of groups. We used two approaches to explore how the 13 substances could be combined into groups of related items. We applied an exploratory factor analysis, but since factor analysis makes assumptions about normality and linear correlations that are likely to be violated by the skewed data, we also used the non-parametric Mokken scaling approach. ${ }^{15}$ The two sets of results taken together supported a division into four groups: (1) medicines (paracetamol, antibiotics, antidepressants, swine flu vaccine and OTC nausea drugs); (2) herbal substances (ginger and cranberries); (3) food substances (eggs and blue-veined cheese); and (4) alcohol and smoking. Thalidomide and dental X-rays did not appear to fit well in any grouping (for further details please see online supplementary appendix 1). For each group we added together the scores and divided this by the number of scores in the group to keep the outcome variable on a scale from 0 to 10 . We conducted a separate analysis for thalidomide and the associations with sociodemographic factors as described below, but did not examine dental X-rays further.

There are a number of missing values in our outcome variables where the women either did not answer the question or ticked 'unknown substance'. Women with missing values are excluded from the corresponding analyseswhere one or more substances contributing to a grouped outcome are missing, the whole grouped outcome is treated as missing. We report the number of individuals included in each analysis (n) along with the results.

We used multilevel linear regression analyses to examine associations between the four grouped risk perception scores and maternal age, education, profession, pregnancy details and geographical regions, with countries as the second level of analysis. We repeated these analyses for thalidomide. A positive coefficient denoted a higher perception of risk than baseline, whereas a negative coefficient denoted a lower perception of risks. All regression models were repeated adjusting for age and education.

Factor analysis and Mokken scaling were carried out in $\mathrm{R}$ for Windows V.2.15.0 ${ }^{16}$ using the "mokken"17 and 'psych' packages. ${ }^{18}$ Multilevel regression analyses were carried out in Stata V.13.

\section{RESULTS}

In total, 9113 women from 18 countries responded to the survey (table 1). The women were aged between 15 and 55 years, with the majority being in the age range of 2635 years $(5935,65 \%)$ (table 1$)$. At the time they responded to the questionnaire, $4938(54 \%)$ were pregnant and the majority were married/cohabiting (8578 (94\%)); for half of the women this was their first child. Many of the women had university or college degrees $(5120(56 \%))$ and were working at the start of the pregnancy (table 1).

In general, women perceived a low risk of giving birth to a child with a birth defect. Thus, of the 8131 women who responded to the question "Among 100 healthy women in a healthy environment, how many do you think will give birth to a child with a birth defect?", nearly $80 \%(6453 / 8131)$ perceived the risk to be less than 5 of 100 births. Yet, $789(10 \%)$ of the women thought the baseline risk to be more than 10 of 100 births. The vast majority of women from Northern Europe $(2296(88 \%))$ perceived the risk to be less than 5 of 100 births and only $110(4 \%)$ thought baseline risks were more than 10 of 100 births. This was in contrast to 93/496 (19\%) women in North America who thought the risks were more than 10 of 100 births. There were 982 who did not know or did not answer the question.

Overall, the women rated cranberries and ginger least harmful and antidepressants, alcohol, smoking and thalidomide as most harmful (figure 1 and table 2). For some items there was a substantial difference between geographical regions (figure 1). For example, mean risk perception scores for antibiotics varied from $3.9(95 \%$ CI 3.5 to 4.3) for Australia to 7.1 (95\% CI 7.0 to 7.2) for Eastern Europe. Large variations were also observed for mean risk perception scores for antidepressants; ranging from 5.9 (95\% CI 5.6 to 6.3) for Australia to 8.5 (95\% CI 8.4 to 8.6) for Eastern Europe-on par with alcohol and not far below that for thalidomide (figure 1). Women from Eastern Europe also perceived the risk of swine flu vaccine to be much higher than women from any of the other geographical regions (figure 1). Noticeably, many women did not know of thalidomide and it was only rated by 2692/9113 (30\%) women. However, of the women who did respond to this question, over $80 \%$ rated thalidomide 10 'very harmful'.

\section{Perception of risks of OTC medicine against nausea, prescription medicine and thalidomide}

For OTC and prescription medicine, the perception of risks was lowest among those aged 31-40 years and 
Figure 1 Mean risk perception scores for 13 individual items by geographical region.

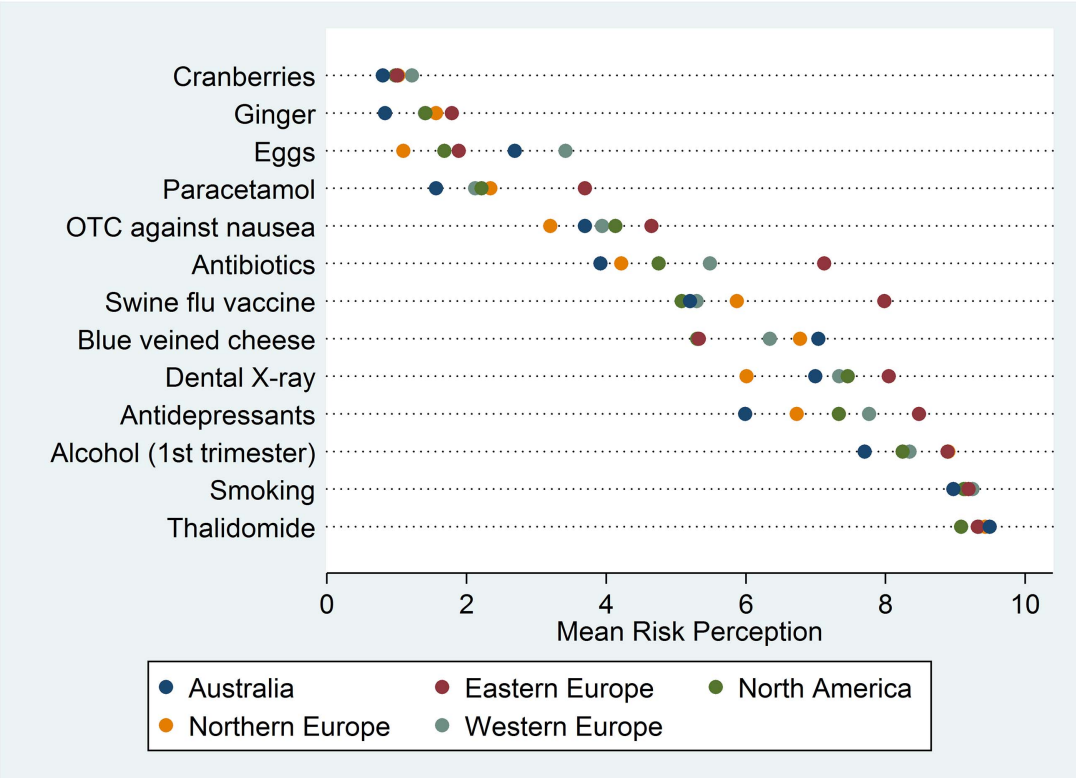

highest among those aged 21-25 years. Risk perception was higher among women educated up to primary school and high-school level; their estimated risk perception scores were 0.36 (95\% CI 0.14 to 0.58 ) and 0.30 (95\% CI 0.20 to 0.40 ) points higher compared to women educated up to university level (table 3). Likewise, women who had their first pregnancy (child) had a higher perception of risks of these medicines, whereas women working as health professionals had a substantially lower perception of risks than women working in other professions (table 3). Women from Eastern Europe had a considerably higher perception of risks of OTC and prescribed medicine than women from Northern Europe-their estimated risk perception score was 1.57 (95\% CI 0.72 to 2.41) points higher than that for women in the Northern Europe reference category.
The estimated perception of risks for thalidomide was higher among older women (estimated risk perception scores were $0.31 \quad(95 \%$ CI 0.13 to 0.50$)$ for those aged 36-40 years), but lower among younger women (estimated risk perception scores were -0.51 (95\% CI -0.98 to -0.04$)$ for those aged 15-20 years in comparison to women aged 26-30 years) (table 3). Individuals with non-university education perceived thalidomide less risky than women with education up to university level (estimated risk perception score for women with only primary level education was $-0.44(95 \%$ CI -0.86 to -0.03) compared to women in the university level reference category (table 3). However, there were no significant differences in perception of risks for thalidomide in relation to profession or pregnancy status (table 3).

Table 2 Descriptive statistics for the risk perception scores of the 13 substances, ordered by mean score

\begin{tabular}{|c|c|c|c|c|c|}
\hline Substance & $\mathbf{n}$ & Median & Mean & SD & $95 \% \mathrm{Cl}$ for the mean \\
\hline Cranberries & 8369 & 0 & 1.1 & 1.9 & (1.0 to 1.1$)$ \\
\hline Ginger & 8318 & 0 & 1.5 & 2.3 & (1.5 to 1.6$)$ \\
\hline Eggs & 8860 & 1 & 2.2 & 2.8 & (2.1 to 2.3$)$ \\
\hline Paracetamol & 8849 & 2 & 2.6 & 2.6 & (2.5 to 2.7$)$ \\
\hline Over-the-counter medicines against nausea & 8038 & 4 & 3.9 & 2.7 & (3.8 to 4.0$)$ \\
\hline Antibiotics & 8811 & 5 & 5.4 & 3.1 & (5.4 to 5.5$)$ \\
\hline Swine influenza vaccine & 8077 & 6 & 6.1 & 3.3 & (6.0 to 6.2$)$ \\
\hline Blue veined cheese (eg, Gorgonzola) & 8444 & 7 & 6.2 & 3.3 & (6.1 to 6.3$)$ \\
\hline Dental X-ray & 8714 & 8 & 7.1 & 3.0 & (7.0 to 7.2$)$ \\
\hline Antidepressants & 8420 & 8 & 7.6 & 2.5 & (7.5 to 7.6$)$ \\
\hline Alcohol during the 1 st trimester & 8783 & 10 & 8.6 & 2.3 & (8.6 to 8.7 ) \\
\hline Smoking (eg, cigarettes) & 8752 & 10 & 9.2 & 1.7 & (9.2 to 9.2$)$ \\
\hline Thalidomide & 2692 & 10 & 9.4 & 1.7 & (9.3 to 9.4$)$ \\
\hline
\end{tabular}

Data from all countries combined, $n=9113$.

Question: Here below is a list with various medicines, food and other substances. Please indicate how harmful you think they are for the fetus in a scale from 0 to 10 , where 0 corresponds to 'not harmful' and 10 to 'very harmful'. If you have not heard before about such substance, tick 'unknown substance'. ('Unknown substance' responses are treated as missing values). 
Table 3 Association between age, education, profession, pregnancy status, geographical region and average risk perception scores for the four groups of outcome variables (OTC and prescription medicines, cranberry and ginger, eggs and blue veined cheese, Alcohol and smoking) and thalidomide

\begin{tabular}{|c|c|c|c|c|c|c|c|}
\hline \multirow[b]{2}{*}{ Predictor } & \multirow[b]{2}{*}{$\mathbf{n}$} & \multicolumn{3}{|l|}{ Unadjusted } & \multicolumn{3}{|l|}{ Adjusted* } \\
\hline & & Coefficient & $95 \% \mathrm{Cl}$ & p Value & Coefficient & $95 \% \mathrm{Cl}$ & p Value \\
\hline \multicolumn{8}{|c|}{ OTC and prescription medicines $(n=6945)$} \\
\hline Age band (years) & & & & $<0.001$ & & & $<0.001$ \\
\hline $15-20$ & 201 & 0.20 & $(-0.05$ to 0.44$)$ & & 0.02 & $(-0.24$ to 0.27$)$ & \\
\hline $21-25$ & 1223 & 0.14 & $(0.03$ to 0.26$)$ & & 0.07 & $(-0.05$ to 0.19$)$ & \\
\hline $26-30$ & 2546 & Ref & - & & Ref & - & \\
\hline $31-35$ & 2012 & -0.21 & $(-0.31$ to -0.11$)$ & & -0.19 & $(-0.29$ to 0.09$)$ & \\
\hline $36-40$ & 817 & -0.24 & $(-0.38$ to -0.10$)$ & & -0.21 & $(-0.34$ to 0.07$)$ & \\
\hline 41-55 & 146 & -0.07 & $(-0.35$ to 0.22$)$ & & -0.04 & $(-0.33$ to 0.24$)$ & \\
\hline Education & & & & $<0.001$ & & & $<0.001$ \\
\hline Primary & 272 & 0.43 & (0.21 to 0.64$)$ & & 0.36 & (0.14 to 0.58$)$ & \\
\hline High-school & 1907 & 0.35 & (0.25 to 0.44$)$ & & 0.30 & (0.20 to 0.40$)$ & \\
\hline University & 3940 & Ref & - & & Ref & - & \\
\hline Other & 826 & 0.28 & (0.15 to 0.41$)$ & & 0.26 & (0.13 to 0.39$)$ & \\
\hline Health professional & 1107 & -0.74 & $(-0.85$ to -0.63$)$ & $<0.001$ & -0.71 & $(-0.82$ to -0.60$)$ & $<0.001$ \\
\hline First pregnancy & 3489 & 0.24 & (0.16 to 0.32$)$ & $<0.001$ & 0.22 & (0.14 to 0.31$)$ & $<0.001$ \\
\hline Pregnant now & 3721 & -0.06 & $(-0.14$ to 0.02$)$ & 0.159 & -0.07 & $(-0.15$ to 0.02$)$ & 0.123 \\
\hline Regions & & & & 0.004 & & & 0.003 \\
\hline \multicolumn{8}{|l|}{ Europe } \\
\hline Northern & 2129 & Ref & - & & Ref & - & \\
\hline Western & 2630 & 0.78 & $(-0.03$ to 1.60$)$ & & 0.81 & $(-0.01$ to 1.62$)$ & \\
\hline Eastern & 1596 & 1.51 & (0.67 to 2.36$)$ & & 1.57 & (0.72 to 2.41$)$ & \\
\hline North America & 415 & 0.41 & $(-0.68$ to 1.50$)$ & & 0.47 & $(-0.62$ to 1.56$)$ & \\
\hline Australia & 175 & -0.27 & $(-1.68$ to 1.14$)$ & & -0.18 & $(-1.59$ to 1.22$)$ & \\
\hline \multicolumn{8}{|l|}{ Thalidomide $(n=2692)$} \\
\hline Age band (years) & & & & $<0.001$ & & & $<0.001$ \\
\hline $15-20$ & 52 & -0.73 & $(-1.19$ to -0.27$)$ & & -0.51 & $(-0.98$ to -0.04$)$ & \\
\hline $21-25$ & 289 & -0.48 & $(-0.70$ to -0.26$)$ & & -0.42 & $(-0.64$ to -0.20$)$ & \\
\hline $26-30$ & 881 & Ref & - & & Ref & - & \\
\hline $31-35$ & 920 & 0.20 & (0.04 to 0.35$)$ & & 0.17 & (0.02 to 0.32$)$ & \\
\hline $36-40$ & 453 & 0.35 & (0.16 to 0.53$)$ & & 0.31 & $(0.13$ to 0.50$)$ & \\
\hline $41-55$ & 97 & 0.18 & $(-0.16$ to 0.53$)$ & & 0.18 & $(-0.17$ to 0.52$)$ & \\
\hline Education & & & & $<0.001$ & & & $<0.001$ \\
\hline Primary & 66 & -0.62 & $(-1.03$ to -0.21$)$ & & -0.44 & $(-0.86$ to -0.03$)$ & \\
\hline High-school & 605 & -0.47 & $(-0.62$ to -0.32$)$ & & -0.36 & $(-0.52$ to -0.20$)$ & \\
\hline University & 1727 & Ref & - & & Ref & - & \\
\hline Other & 294 & -0.17 & $(-0.37$ to 0.04$)$ & & -0.10 & $(-0.31$ to 0.11$)$ & \\
\hline Health professional & 694 & 0.21 & $(0.07$ to 0.36$)$ & 0.004 & 0.13 & $(-0.02$ to 0.27$)$ & 0.091 \\
\hline First pregnancy & 1256 & -0.05 & $(-0.18$ to 0.07$)$ & 0.401 & 0.03 & $(-0.10$ to 0.16$)$ & 0.615 \\
\hline Pregnant now & 1382 & -0.12 & $(-0.25$ to 0.01$)$ & 0.061 & -0.08 & $(-0.21$ to 0.05$)$ & 0.212 \\
\hline Regions & & & & 0.577 & & & 0.724 \\
\hline \multicolumn{8}{|l|}{ Europe } \\
\hline Northern & 708 & Ref & - & & Ref & - & \\
\hline Western & 1259 & 0.08 & $(-0.29$ to 0.45$)$ & & 0.07 & $(-0.30$ to 0.43$)$ & \\
\hline Eastern & 443 & -0.05 & $(-0.45$ to 0.34$)$ & & -0.01 & $(-0.40$ to 0.37$)$ & \\
\hline North America & 186 & -0.30 & $(-0.80$ to 0.20$)$ & & -0.27 & $(-0.77$ to 0.22$)$ & \\
\hline Australia & 96 & 0.13 & $(-0.51$ to 0.77$)$ & & 0.03 & $(-0.61$ to 0.66$)$ & \\
\hline \multicolumn{8}{|c|}{ Cranberries and ginger $(n=8058)$} \\
\hline Age band (years) & & & & 0.064 & & & 0.065 \\
\hline $15-20$ & 258 & 0.19 & (-0.04 to 0.43$)$ & & 0.17 & (-0.07 to 0.42$)$ & \\
\hline $21-25$ & 1447 & 0.05 & $(-0.06$ to 0.17$)$ & & 0.04 & $(-0.07$ to 0.16$)$ & \\
\hline $26-30$ & 2946 & Ref & - & & Ref & - & \\
\hline $31-35$ & 2333 & 0.05 & $(-0.05$ to 0.15$)$ & & 0.05 & $(-0.05$ to 0.15$)$ & \\
\hline $36-40$ & 912 & 0.20 & $(0.06$ to 0.34$)$ & & 0.21 & (0.07 to 0.35 ) & \\
\hline 41-55 & 162 & 0.18 & $(-0.11$ to 0.48$)$ & & 0.19 & $(-0.10$ to 0.48$)$ & \\
\hline Education & & & & 0.780 & & & 0.798 \\
\hline Primary & 310 & 0.03 & $(-0.19$ to 0.24$)$ & & 0.01 & $(-0.21$ to 0.24$)$ & \\
\hline High-school & 2202 & 0.05 & $(-0.05$ to 0.15$)$ & & 0.05 & $(-0.05$ to 0.15$)$ & \\
\hline
\end{tabular}


Table 3 Continued

\begin{tabular}{|c|c|c|c|c|c|c|c|}
\hline \multirow[b]{2}{*}{ Outcome } & \multirow[b]{2}{*}{$\mathbf{n}$} & \multicolumn{3}{|l|}{ Unadjusted } & \multicolumn{3}{|l|}{ Adjusted* } \\
\hline & & Coefficient & $95 \% \mathrm{Cl}$ & p Value & Coefficient & $95 \% \mathrm{Cl}$ & p Value \\
\hline University & 4631 & Ref & - & & Ref & - & \\
\hline Other & 915 & 0.00 & $(-0.13$ to 0.14$)$ & & 0.00 & $(-0.13$ to 0.14$)$ & \\
\hline Health professional & 1124 & 0.08 & $(-0.03$ to 0.20$)$ & 0.165 & 0.10 & $(-0.02$ to 0.22$)$ & 0.102 \\
\hline First pregnancy & 4066 & 0.04 & $(-0.04$ to 0.13$)$ & 0.282 & 0.06 & $(-0.02$ to 0.15$)$ & 0.139 \\
\hline Pregnant now & 4353 & -0.03 & $(-0.11$ to 0.05$)$ & 0.510 & -0.02 & $(-0.10$ to 0.06$)$ & 0.651 \\
\hline Regions & & & & 0.450 & & & 0.461 \\
\hline \multicolumn{8}{|l|}{ Europe } \\
\hline Northern & 2584 & Ref & - & & Ref & - & \\
\hline Western & 2719 & 0.29 & $(-0.27$ to 0.85$)$ & & 0.27 & $(-0.28$ to 0.83$)$ & \\
\hline Eastern & 2076 & $<0.01$ & $(-0.58$ to 0.58$)$ & & 0.01 & $(0.57$ to 0.58$)$ & \\
\hline North America & 473 & -0.12 & $(-0.86$ to 0.63$)$ & & -0.12 & $(-0.86$ to 0.62$)$ & \\
\hline Australia & 206 & -0.50 & $(-1.46$ to 0.47$)$ & & -0.52 & $(-1.48$ to 0.44$)$ & \\
\hline \multicolumn{8}{|c|}{ Egg and blue veined cheese $(n=8339)$} \\
\hline Age band (years) & & & & $<0.001$ & & & 0.002 \\
\hline $15-20$ & 243 & -0.09 & $(-0.39$ to 0.22$)$ & & -0.15 & $(-0.46$ to 0.17$)$ & \\
\hline $21-25$ & 1464 & 0.09 & $(-0.06$ to 0.23$)$ & & 0.06 & $(-0.08$ to 0.21$)$ & \\
\hline $26-30$ & 3034 & Ref & - & & Ref & - & \\
\hline $31-35$ & 2456 & -0.14 & $(-0.26$ to -0.01$)$ & & -0.13 & $(-0.26$ to -0.01$)$ & \\
\hline $36-40$ & 970 & -0.13 & $(-0.30$ to 0.04$)$ & & -0.12 & $(-0.29$ to 0.05$)$ & \\
\hline $41-55$ & 172 & -0.66 & $(-1.02$ to -0.30$)$ & & -0.66 & $(-1.01$ to -0.30$)$ & \\
\hline Education & & & & 0.033 & & & 0.101 \\
\hline Primary & 319 & 0.11 & $(-0.15$ to 0.38$)$ & & 0.10 & $(-0.18$ to 0.37$)$ & \\
\hline High-school & 2318 & 0.13 & (0.01 to 0.25$)$ & & 0.10 & $(-0.02$ to 0.22$)$ & \\
\hline University & 4751 & Ref & - & & Ref & - & \\
\hline Other & 951 & 0.20 & (0.04 to 0.37$)$ & & 0.19 & (0.02 to 0.36$)$ & \\
\hline Health professional & 1169 & -0.06 & $(-0.20$ to 0.09$)$ & 0.452 & -0.05 & $(-0.19$ to 0.10$)$ & 0.545 \\
\hline First pregnancy & 4219 & 0.29 & (0.19 to 0.39$)$ & $<0.001$ & 0.28 & $(0.17$ to 0.39$)$ & $<0.001$ \\
\hline Pregnant now & 4497 & 0.14 & (0.04 to 0.25$)$ & 0.006 & 0.13 & (0.03 to 0.24$)$ & 0.011 \\
\hline Regions & & & & 0.010 & & & 0.008 \\
\hline \multicolumn{8}{|l|}{ Europe } \\
\hline Northern & 2654 & Ref & & & Ref & & \\
\hline Western & 2993 & 0.81 & (0.06 to 1.56$)$ & & 0.83 & (0.09 to 1.58$)$ & \\
\hline Eastern & 2035 & -0.22 & $(-1.00$ to 0.55$)$ & & -0.20 & $(-0.97$ to 0.57$)$ & \\
\hline North America & 446 & -0.47 & $(-1.47$ to 0.53$)$ & & -0.44 & $(-1.44$ to 0.55$)$ & \\
\hline Australia & 211 & 0.88 & $(-0.41$ to 2.18$)$ & & 0.94 & $(-0.35$ to 2.22$)$ & \\
\hline \multicolumn{8}{|c|}{ Alcohol and smoking $(n=8701)$} \\
\hline Age band (years) & & & & 0.003 & & & 0.005 \\
\hline $15-20$ & 278 & -0.27 & $(-0.48$ to -0.06$)$ & & -0.25 & $(-0.47$ to -0.03$)$ & \\
\hline $21-25$ & 1583 & -0.08 & $(-0.19$ to 0.02$)$ & & -0.08 & $(-0.19$ to 0.03$)$ & \\
\hline 26-30 & 3161 & Ref & - & & Ref & - & \\
\hline 31-35 & 2509 & -0.14 & $(-0.23$ to -0.04$)$ & & -0.14 & $(-0.23$ to -0.05$)$ & \\
\hline $36-40$ & 988 & -0.11 & $(-0.24$ to 0.01$)$ & & -0.12 & $(-0.24$ to 0.01$)$ & \\
\hline $41-55$ & 182 & -0.37 & $(-0.63$ to -0.11$)$ & & -0.37 & $(-0.63$ to -0.11$)$ & \\
\hline Education & & & & 0.542 & & & 0.694 \\
\hline Primary & 358 & 0.13 & $(-0.32$ to 0.06$)$ & & 0.10 & $(-0.30$ to 0.09$)$ & \\
\hline High-school & 2432 & 0.01 & $(-0.09$ to 0.08$)$ & & 0.00 & $(-0.09$ to 0.09$)$ & \\
\hline University & 4912 & Ref & - & & Ref & - & \\
\hline Other & 999 & 0.03 & $(-0.10$ to 0.15$)$ & & 0.03 & $(-0.09$ to 0.15$)$ & \\
\hline Health professional & 1188 & 0.10 & $(-0.01$ to 0.21$)$ & 0.072 & 0.09 & $(-0.02$ to 0.20$)$ & 0.114 \\
\hline First pregnancy & 4382 & -0.02 & $(-0.09$ to 0.06$)$ & 0.637 & -0.03 & $(-0.11$ to 0.04$)$ & 0.403 \\
\hline Pregnant now & 4702 & -0.04 & $(-0.11$ to 0.04$)$ & 0.347 & -0.04 & $(-0.12$ to 0.03$)$ & 0.272 \\
\hline Regions & & & & 0.284 & & & 0.274 \\
\hline \multicolumn{8}{|l|}{ Europe } \\
\hline Northern & 2699 & Ref & - & & Ref & - & \\
\hline Western & 3047 & -0.11 & $(-0.48$ to 0.26$)$ & & -0.10 & $(-0.46$ to 0.27$)$ & \\
\hline Eastern & 2261 & -0.19 & (0.57 to 0.19$)$ & & -0.20 & (0.58 to 0.18$)$ & \\
\hline North America & 485 & -0.32 & $(-0.82$ to 0.18$)$ & & -0.32 & $(-0.81$ to 0.18$)$ & \\
\hline Australia & 212 & -0.68 & $(-1.33$ to -0.03$)$ & & -0.67 & $(-1.31$ to -0.02$)$ & \\
\hline
\end{tabular}

Significant findings are marked in bold.

${ }^{*}$ Adjusted analyses were all adjusted for age and education. 
Risk perception of selected food items

For eggs and blue veined cheese, those aged 31-35 and 41-55 years had a lower perception of risks than women aged 26-30 years (table 3); the estimated risk perception score for women aged $41-55$ years was -0.66 (95\% CI -1.01 to -0.30 ) compared to women in the 26-30 years reference category. Women from Western Europe had a higher perception of risks than women from Northern Europe, and so did women who were currently pregnant and pregnant with their first child. For cranberry and ginger, there were no differences associated with age, education, pregnancy status or geographical region (table 3).

\section{Alcohol and smoking}

For alcohol and smoking, the youngest (15-20 years) and the oldest (41-55 years) women perceived these substances less risky relative to women aged 26-30 years (table 3). There were no differences in perception of risks associated with education, pregnancy status or geographical region.

\section{DISCUSSION}

\section{Summary of main findings}

This is the first large scale multinational study of women's perception of risks on a range of substances taken during pregnancy. Overall, perceived risk of giving birth to a child with a birth defect was low, but there were variations between geographical regions. Women rated antidepressants, alcohol, smoking and thalidomide the most harmful, and cranberries and ginger as the least harmful. There were large individual and geographical variations in the perception of risks of OTC and prescribed medication such as antibiotics, swine flu vaccine and antidepressants. Women from Eastern Europe and women of lower ages, less education and first pregnancy perceived the risks to be highest. For thalidomide, associations with age and education were reversed.

\section{Comparisons with other studies}

Perception of risks of OTC, prescribed medication and thalidomide

The US Food and Drug Administration has developed a rule set to define teratogenic medicines based on evidence from animal and human studies. In general, very few medicines are considered teratogenic. ${ }^{19}$ Nevertheless, our study suggests that women across Europe, North America and Australia have severe concerns about the safety of many medicines. Women from Eastern Europe reported a lower usage of OTC and prescribed medicines, but a higher usage of herbal remedies compared to women from other geographical regions. ${ }^{20}{ }^{21}$ This may represent a general scepticism to conventional prescribed medication among Eastern European women. Our findings that risk perceptions of OTC and prescribed medication were lower with increasing age, higher level of education and for women working in health professions may reflect women's access to information and experience. ${ }^{4}$

Although we found a high level of agreement between women and geographical regions on the potential harmful effects of thalidomide, it was rather surprising that only $30 \%$ reported on this item in the survey. Overall, our findings suggest that the general awareness among women of the teratogenic effects of thalidomide is declining, but that the thalidomide scandal ${ }^{1}$ has left a legacy of general scepticism about safety of medication in pregnancy. This scepticism may have been fuelled by many observational studies in recent years on adverse effects of medicines in pregnancy, in particular antidepressants. ${ }^{22-24}$ Although the evidence is conflicting and many studies lack the ability to control for potential confounding factors, ${ }^{25-27}$ the uncertainty about the adverse effects may translate into a general disbelief or distrust in the safety of medication. Hence, studies suggest that if the information is conflicting many women choose not to take the medication. ${ }^{4} 28$

\section{Risk perception of selected food items and herbal remedies}

Women are generally advised not to consume blue veined cheese and uncooked eggs in pregnancy due to the risks of listeria and salmonella infections. ${ }^{29} \mathrm{We}$ observed that women who were pregnant at the time of the survey or who experienced their first pregnancy perceived the risks to be highest. These women may be the most alert to such advice and therefore, perceived the risks to be higher. Women in Western Europe, in particular, were concerned about the safety of these items. This may be associated with a higher consumption and/or prevalence of these infections in Western Europe, but may also represent differences in public health communication. The ginger and cranberry are commonly used herbal remedies in pregnancy, ${ }^{20} 21$ and our findings that women perceived these to be safe are in line with a more general perception of herbal products being safe in pregnancy, although the evidence base for herbal remedies is often poor. ${ }^{21} 30$

\section{Risk perception of alcohol and tobacco}

Our findings that the alcohol and smoking were perceived to carry high risks in pregnancy is similar to findings of other studies. ${ }^{41}$ However, it was noticeable that the very youngest and oldest women perceived smoking and alcohol to be less risky. Both substances are considered harmful to the unborn child although there are still debates about whether there is a safe threshold for drinking alcohol during pregnancy. A small qualitative study revealed that women found information and advice about safe levels of drinking in pregnancy confusing, and lacking in evidence and detail. ${ }^{32}$

\section{Strength and limitations}

This is the first large-scale multinational survey of women's actual perception of risks of a range of 
substances in pregnancy. A major strength of the study is the large numbers of participants from countries across Europe, North America and Australia. This made it possible to conduct cross-regional comparisons of the perceived risks and enable generalisation of findings on larger geographical scales.

Internet surveys are often criticised for not having a standardised sampling frame and the potential for selection bias towards the more literate population. ${ }^{33}$ Yet, the internet penetration rate is high among women in this study population and a comparison with the population of women giving birth in each of the participating countries suggests that the study samples were roughly similar (see web appendices ${ }^{20}$ ). However, we adjusted all our analyses for age and education to take into account regional differences. Also, women who took part in the survey may have been women who were more alert to adverse birth effects for one reason or another. Hence, our survey may overestimate the perception of risks among the general population of women in childbearing age.

Our survey did not go into detailed questioning about women's perception of what constitute harmful effects, but left this to the individual women to define. It is likely, however, that many women may have interpreted our question broadly and considered factors such as congenital anomalies, still birth, preterm birth, low birth weight, growth retardation of the fetus and developmental delays in totality. To further disentangle women's concept of risks, more in-depth qualitative research may be required as has been done by Heaman et al. ${ }^{11}$

\section{Clinical implications}

This study reveals substantial disparity between women's perceived risks and the actual risks when it comes to OTC agents and prescribed medication. As a consequence, some women are likely to be left without medical treatments in pregnancy, which may have detrimental consequences. For example, pyelonephritis following untreated urinary tract infections can result in significant maternal and fetal morbidity and mortality. ${ }^{34}$ Likewise, it is well recognised that prior depression is a risk factor for postnatal depression and untreated depression might have important consequences for pregnancy outcomes. ${ }^{35} 36$ Further, important clinical implications arise when women who take medication before their pregnancy was known perceive these medications to be teratogenic. They may be left with a high level of anxiety about damage done to the unborn child, and some women in such situation might even seek to terminate the pregnancy of otherwise wanted children. ${ }^{37}$ However, research has demonstrated that counselling and advice about the risks may prevent unjustified termination of many pregnancies. ${ }^{10} 38-40$ Our study highlighted the regional and sociodemographic differences in risk perceptions. For example, we found that women in Eastern Europe on average rated OTC and prescription medicines 1.57 (95\% CI 0.72 to 2.41) points higher than women in Northern Europe. On a scale from 0 to 10 , this implies a substantial regional difference in risk perception. The effects of other sociodemographic characteristics on risk perception were less stark. However, we noticed that profession, education, age and parity had an impact on women's risk perception. For example, women in their first pregnancy on average rated OTC and prescription medicines 0.22 (95\% CI 0.14 to 0.31 ) points higher than other women. This suggests that there is a need to tailor and adapt future communication of risks and benefits to specific groups of women and geographical regions.

Our study suggests that there is a need to raise the awareness of how risks and benefits of medicine are communicated and perceived. General practitioners (family doctors), pharmacists, midwives, nurses and other healthcare professionals may have a pivotal role in advising women on potential risks and benefits of prescribed medicine and other items in pregnancy. ${ }^{4}$ The language and the communication of risks may be paramount to women's decision on whether to stop or continue medication in pregnancy. ${ }^{41}$ We should also be aware that while much research focuses on specific adverse birth outcomes, in clinical practice women may not distinguish between these outcomes, their prevalence and severity.

\section{CONCLUSION}

This study suggests that women perceive the risks of giving birth to a child with birth defects to be low, but demonstrated a substantial disparity between women's perceived risks and the actual risks when it comes to OTC agents and prescribed medication. The study revealed that few women now know of thalidomide, suggesting that the general awareness among women of the teratogenic effects of thalidomide is declining. However, the past thalidomide scandal has left behind a general scepticism about safety of medication in pregnancy and this may have some severe consequences.

\section{Twitter Follow Hedvig Nordeng at @Pharma_Nordeng}

Acknowledgements The authors thank the Steering Committee of OTIS and ENTIS for reviewing the protocol, all website providers who contributed to the recruitment phase and all the study national coordinators (Twigg MJ, Zagorodnikova K, Mårdby AC, Moretti ME, Drozd M, Panchaud A, Hameen-Anttila K, Rieutord A, Gjergja Juraski R, Odalovic M, Kennedy D, Rudolf G, Juch H, Passier JLM and Björnsdóttir I). The authors are grateful to all the participating women who took part in this study.

Contributors IP wrote the first draft of the paper; IP, HN, RLMC, AL contributed to the final draft. RLM did the analysis of the data. IP, HN, RLMC, AL contributed to the study design, analysis and interpretation of the results. IP is the guarantor.

Funding The study received funding from Norwegian Research Council (grant no. 216771/F11). The funding source did not participate in the study design, analysis and interpretation of results or the decision to submit this manuscript for publication.

Competing interests None declared.

Ethics approval All participants gave informed consent by answering "Yes" to the question "Are you willing to participate in the study?" The study was 
approved by the Regional Ethics Committee, Region South-East in Norway. Ethical approval or study notification to the relevant national Ethics Boards was achieved in specific countries as required by national legislation. All data were handled and stored anonymously.

Provenance and peer review Not commissioned; externally peer reviewed.

Data sharing statement Researchers can apply for data access for subprojects within the overall aims of the main study 'The Multinational Medication Use in Pregnancy Study'.

Transparency The lead author affirms that the manuscript is an honest, accurate and transparent account of the study being reported

Open Access This is an Open Access article distributed in accordance with the Creative Commons Attribution Non Commercial (CC BY-NC 4.0) license which permits others to distribute, remix, adapt, build upon this work noncommercially, and license their derivative works on different terms, provided the original work is properly cited and the use is non-commercial. See: http:// creativecommons.org/licenses/by-nc/4.0/

\section{REFERENCES}

1. McBride W. Thalidomide and congenital abnormalities. Lancet 1961;2:1358.

2. Petersen I, Gilbert RE, Evans SJW, et al. Pregnancy as a major determinant for discontinuation of antidepressants: an analysis of data from The Health Improvement Network. J Clin Psychiatry 2011;72:979-85.

3. Man SL, Petersen I, Thompson M, et al. Antiepileptic drugs during pregnancy in primary care: a UK population based study. PLOS ONE 2012;7:e52339.

4. Nordeng $\mathrm{H}$, Ystrom E, Einarson A. Perception of risk regarding the use of medications and other exposures during pregnancy. Eur $J$ Clin Pharmacol 2010;66:207-14.

5. Lupattelli A, Spigset O, Nordeng H. Adherence to medication for chronic disorders during pregnancy: results from a multinational study. Int J Clin Pharm 2014;36:145-53.

6. Sanz E, Gómez-López T, Martínez-Quintas MJ. Perception of teratogenic risk of common medicines. Eur J Obstet Gynecol Reprod Biol 2001;95:127-31.

7. Petersen I, McCrea RL, Osborn DJP, et al. Discontinuation of antipsychotic medication in pregnancy: a cohort study. Schizophr Res 2014;159:218-25.

8. Larsson M. A descriptive study of the use of the Internet by women seeking pregnancy-related information. Midwifery 2009;25:14-20.

9. Nordeng H, Koren G, Einarson A. Pregnant women's beliefs about medications-a study among 866 norwegian women. Ann Pharmacother 2010;44:1478-84.

10. Koren $\mathrm{G}$, Bologa $\mathrm{M}$, Long $\mathrm{D}$, et al. Perception of teratogenic risk by pregnant women exposed to drugs and chemicals during the first trimester. Am J Obstet Gynecol 1989;160(5 Pt 1):1190-4.

11. Heaman M, Gupton A, Gregory D. Factors influencing pregnant women's perceptions of risk. MCN Am J Matern Child Nurs 2004;29:111-16.

12. Bayrampour H, Heaman M, Duncan KA, et al. Comparison of perception of pregnancy risk of nulliparous women of advanced maternal age and younger age. J Midwifery Womens Health 2012;57:445-53.

13. Bayrampour $\mathrm{H}$, Heaman $\mathrm{M}$, Duncan KA, et al. Predictors of perception of pregnancy risk among nulliparous women. J Obstet Gynecol Neonatal Nurs 2013;42:416-27.

14. Gupton A, Heaman M, Cheung LW. Complicated and uncomplicated pregnancies: women's perception of risk. J Obstet Gynecol Neonatal Nurs 2001;30:192-201.

15. Sijtsma K, Molenaar IW. Introduction to nonparametric item response theory. Thousand Oaks, California: Sage Publications, 2002.

16. R Core Team. R: A Language and Environment for Statistical Computing. Vienna, Austria, 2012. http://www.R-project.org/

17. Van der Ark LA. Mokken scale analysis in R. J Stat Softw 2007;20:1-19.

18. Revelle W. Psych: procedures for psychological, psychometric, and personality research. Evanston, Illinois: Northwestern University, 2013. http://CRAN.R-project.org/package=psych
19. Labeling > Summary of Proposed Rule on Pregnancy and Lactation Labeling. (cited 22 Jun 2014). http://www.fda.gov/drugs/ developmentapprovalprocess/developmentresources/labeling/ ucm093310.htm

20. Lupattelli A, Spigset O, Twigg MJ, et al. Medication use in pregnancy: a cross-sectional, multinational web-based study. BMJ Open 2014;4:e004365.

21. Kennedy DA, Lupattelli A, Koren G, et al. Herbal medicine use in pregnancy: results of a multinational study. BMC Complement Altern Med 2013;13:355

22. Pedersen LH, Henriksen TB, Vestergaard M, et al. Selective serotonin reuptake inhibitors in pregnancy and congenital malformations: population based cohort study. Br Med J 2009;339: b3569.

23. Malm H, Artama M, Gissler M, et al. Selective serotonin reuptake inhibitors and risk for major congenital anomalies. Obstet Gynecol 2011;118:111-20.

24. Ban L, Gibson J, West J, et al. Maternal depression, antidepressant prescriptions, and congenital anomaly risk in offspring: a population-based cohort study. BJOG 2014;121:1471-81.

25. Grigoriadis S, VonderPorten EH, Mamisashvili L, et al. The effect of prenatal antidepressant exposure on neonatal adaptation: a systematic review and meta-analysis. J Clin Psychiatry 2013;74:e309-20.

26. Wurst KE, Poole C, Ephross SA, et al. First trimester paroxetine use and the prevalence of congenital, specifically cardiac, defects: a meta-analysis of epidemiological studies. Birth Defects Res A Clin Mol Teratol 2010;88:159-70.

27. Huybrechts KF, Palmsten K, Avorn J, et al. Antidepressant use in pregnancy and the risk of cardiac defects. $N$ Engl J Med 2014;370:2397-407.

28. Hämeen-Anttila $\mathrm{K}$, Nordeng $\mathrm{H}$, Kokki $\mathrm{E}$, et al. Multiple information sources and consequences of conflicting information about medicine use during pregnancy: a multinational internet-based survey. J Med Internet Res 2014;16:e60.

29. Foods to avoid during pregnancy-Health questions-NHS Choices (cited 16 June 2014). http://www.nhs.uk/chq/Pages/917.aspx? CategorylD=54\#close

30. Holst L, Wright $\mathrm{D}$, Nordeng $\mathrm{H}$, et al. Use of herbal preparations during pregnancy: focus group discussion among expectant mothers attending a hospital antenatal clinic in Norwich, UK. Complement Ther Clin Pract 2009;15:225-9.

31. Peadon E, Payne J, Henley N, et al. Women's knowledge and attitudes regarding alcohol consumption in pregnancy: a national survey. BMC Public Health 2010;10:510.

32. Raymond N, Beer C, Glazebrook C, et al Pregnant women's attitudes towards alcohol consumption. BMC Public Health 2009;9:175.

33. Ekman A, Dickman PW, Klint Å, et al. Feasibility of Using Web-based Questionnaires in large population-based epidemiological studies. Eur J Epidemiol 2006;21:103-11.

34. Millar LK, Cox SM. Urinary tract infections complicating pregnancy. Infect Dis Clin North Am 1997;11:13-26.

35. O'hara MW, Swain AM. Rates and risk of postpartum depression-a meta-analysis. Int Rev Psychiatry 1996;8:37-54.

36. Grote NK, Bridge JA, Gavin AR, et al. A meta-analysis of depression during pregnancy and the risk of preterm birth, low birth weight, and intrauterine growth restriction. Arch Gen Psychiatry 2010;67:1012-24

37. Einarson A, Choi J, Einarson TR, et al. Rates of spontaneous and therapeutic abortions following use of antidepressants in pregnancy: results from a large prospective database. J Obstet Gynaecol Can 2009;31:452-6.

38. Walfisch A, Sermer C, Matok I, et al. Perception of teratogenic risk and the rated likelihood of pregnancy termination: association with maternal depression. Can J Psychiatry Rev Can Psychiatr 2011;56:761-7

39. The Hospital for Sick Children-Motherisk-Drugs in Pregnancy (cited 5 July 2014). http://www.motherisk.org/women/drugs.jsp

40. UKTIS. (cited 5 July 2014). http://www.uktis.org/

41. Pole M, Einarson A, Pairaudeau N, et al. Drug labeling and risk perceptions of teratogenicity: a survey of pregnant Canadian women and their health professionals. J Clin Pharmacol 2000:40:573-7. 